\title{
Relevance of the composition of municipal plastic wastes for metallurgical coke production
}

\author{
S. Melendi, M.A. Diez*, R. Alvarez, C. Barriocanal \\ Instituto Nacional del Carbón (INCAR), CSIC, Apartado 73, 33080 Oviedo, Spain
}

\section{A R T I C L E I N F O}

\section{Article history:}

Received 26 May 2010

Received in revised form 3 December 2010

Accepted 6 January 2011

Available online 18 January 2011

\section{Keywords:}

Coal

Plastic wastes

Rheology

Coking pressure

Metallurgical coke

\begin{abstract}
A B S T R A C T
This study is concerned with the effects of the composition of mixed plastic wastes on the thermoplastic properties of coal, the generation of coking pressure and the quality of the resulting cokes in a movable wall oven at semipilot scale. The mixed plastic wastes were selected to cover a wide spectrum in the relative proportions of high- and low-density polyethylenes (HDPE and LDPE), polypropylene (PP), polystyrene (PS) and polyethylene terephthalate (PET). From the results it was deduced that the reduction in Gieseler fluidity in the coal blend is linked to the total amount of polyolefins in the waste. It was also found that these thermoplastics increase the pressure exerted against the wall in the course of the coking process and that coke quality is maintained or even improved. However, when the level of aromatic polymers such PS and PET are increased at the expense of polyolefins, the coking pressure decreases. Thus, the amount of aromatic polymers such as PS and PET in the waste is critical, not only for controlling Gieseler fluidity and coking pressure, but also for avoiding deterioration in coke quality (reactivity towards $\mathrm{CO}_{2}$ $-\mathrm{CRI}-$ and mechanical strength of the partially-gasified coke -CSR-). An amount of polyolefins in the waste lower than 65 wt.\% for a secure coking pressure is established.
\end{abstract}

(c) 2011 Elsevier Ltd. All rights reserved.

\section{Introduction}

Alternative plastic waste recycling by methods other than mechanical, chemical and energy recovery processes is of great interest for minimizing environmental damage, especially when the waste plastics can be incorporated as a feedstock into already existing processes. The carbonization of coal to produce metallurgical coke is considered as one possible route for recycling plastic wastes of different structure and origin. Recently, integrated steel plants made a further contribution to plastics recycling by applying it to the blast furnace [1-6] and the carbonization processes [7-16]. In 2000, the Nippon Steel Corporation (NSC) began the industrial application of plastic wastes as minor components of coal blends for blast-furnace coke production at the Nagoya and Kimitsu works with a recycling capacity of 80,000 t/year [8,9].

Previous investigations on the modifications induced by different types of plastics on coal rheology [16-23] and metallurgical coke structure and properties [7-16] have mostly concentrated on the use of single polymers or mixed plastic wastes of a specific composition. As regards the development of coal fluidity, it has been reported by several authors that the plastics can be categorized into two major groups: (i) polyolefins such as polyethylenes (PE) and polypropylene (PP) which are weak modifiers of the

\footnotetext{
* Corresponding author.

E-mail address: madiez@incar.csic.es (M.A. Diez).
}

fluidity/viscosity of coking coals or coal blends; and (ii) aromatic polymers such as polystyrene (PS) and polyethylene terephthalate (PET), which are the strong modifiers. Furthermore, certain types of plastics such as polyolefins can be incorporated into typical coking blends as secondary raw materials in small amounts of less than 3 wt.\% without significantly modifying coke properties. Preliminary data obtained from the use of polyethylene wastes as a minor component in coal blends, carbonized at semi-industrial scale in the INCAR Coking Test Plant, showed that the coal blend used can tolerate up to $3 \mathrm{wt}$.\% of plastic waste without any significant deterioration in the coke quality parameters [13]. However, when polyolefins in small quantities are added to the coal, the coke quality is maintained or even slightly improved, but the pressure generated during the coking process increases. Nomura and Kato [10] find that the particle size of plastic waste seems to be a critical factor for the development of the coking pressure. Polyethylene (PE) in the form of powder or beads increases internal gas pressure in about 3.5-3.8 times in comparison of the pressure generated by the coal without plastic addition. A possible explanation was found in the PE decomposition gas which can be trapped in the coal plastic layer, which results in a gas permeability quite low. However, large agglomerated mixed plastic waste of $25 \mathrm{~mm}$ in size does not affected the coking pressure and it is kept in much lower values than the PE.

The purpose of this study is to gain further insight into the effects of adding plastic wastes to coal blends for use in blast-furnace coke 
production. Mixed plastic wastes frequently found in municipal wastes, which vary in composition, were added to an industrial coal blend in amounts of $2 \mathrm{wt}$.\% as a means of assessing the modifications of the thermoplastic properties of the coal blend, the influence on coking pressure developed and the quality of the metallurgical coke produced. Furthermore, the viability in using plastic wastes in cokemaking, it is shown to be a balance between the relative proportion of polyolefins to aromatic polymers such as PET and PS.

\section{Experimental}

\subsection{Materials}

A typical coal blend used in industrial blast-furnace coke production was employed for preparing the mixtures with the selected plastic wastes. The main characteristics of this coking blend are: 23.8 wt.\% db volatile matter; 9 wt.\% db ash; 0.65 wt.\% $\mathrm{db}$ sulphur; $214 \mathrm{ddpm}$ Gieseler maximum fluidity; and, minus $20 \mathrm{~mm}$ Koppers-INCAR contraction. Six mixed plastic wastes representing the most common thermoplastics present in municipal wastes were added as additives to the coal blend. Four of them (W1A, W1B, W1C, W4) were provided by the Spanish recycling company ABORNASA together with a single multicolour HDPE waste. Wastes W2 and W3 were prepared by blending W4 with HDPE in order to increase the total polyolefin content in the waste (Table 1 ). Waste composition data were provided by the recycling company and they are based on the manual sorting of each type of plastic in the waste.

\subsection{Gieseler plastometry}

Changes in the plasticity of the coal + plastic mixtures were measured using a R.B. Automazione PL2000 Gieseler plastometer, following the ASTM D2639 standard procedure. This instrument measures the rotation of a stirrer inside a compacted powder sample $(5 \mathrm{~g},<0.425 \mathrm{~mm})$, while it is being heated from $300^{\circ} \mathrm{C}$ up to $550{ }^{\circ} \mathrm{C}$ at a heating rate of $3{ }^{\circ} \mathrm{C} / \mathrm{min}$. During the test, the fluidity is recorded in dial divisions per minute (ddpm) as a function of the temperature. The fluidity increases to a maximum value (Fmax) and, then, as the temperature increases, it decreases to zero ddpm with the formation of semicoke. The characteristic temperatures in the development of coal fluidity are: softening temperature (Ts), maximum fluidity temperature (Tf) and resolidification temperature ( $\mathrm{Tr}$ ). The plastic/fluid range is defined as the difference between the resolidification and softening temperatures. For the Gieseler fluidity measurements, each plastic waste, cryogenically ground to a particle size of less than $0.4 \mathrm{~mm}$, was physically mixed with the coal blend in amounts of $2 \mathrm{wt} . \%$.

\subsection{Co-carbonization in a movable wall oven}

The coal blend and its mixtures with the different plastic wastes were carbonized in a semipilot moveable-wall oven of

Table 1

Composition of the mixed plastic wastes.

\begin{tabular}{llllrrr}
\hline & W1A & W1B & W1C & W2 & W3 & W4 \\
\hline HDPE & 70.0 & 73.0 & 70.0 & 55.4 & 37.5 & 10.7 \\
LDPE & 5.0 & 0.0 & 5.0 & 2.7 & 3.8 & 5.4 \\
PP & 20.0 & 20.0 & 20.0 & 19.6 & 27.4 & 39.2 \\
PS & 0.0 & 0.0 & 0.0 & 8.3 & 11.6 & 16.6 \\
PET & 5.0 & 5.0 & 5.0 & 9.4 & 13.2 & 18.8 \\
PVC & 0.0 & $<0.1$ & 0.0 & 0.6 & 0.8 & 1.2 \\
Cellulose & $<1.0$ & 2.0 & $<1.0$ & 0.6 & 0.8 & 1.2 \\
Non-identified & - & - & - & 3.5 & 4.8 & 6.9 \\
Polyolefins & 95.0 & 93.0 & 95.0 & 77.7 & 68.7 & 55.3 \\
\hline
\end{tabular}

over $15 \mathrm{~kg}$ capacity [15]. The oven walls were electrically heated. One of them is movable so that the force exerted on the wall during carbonization can be measured by means of a load cell (1 tonne). Coking pressure is defined as the force per unit wall area. A thermocouple was inserted in the centre of the charge to monitor the temperature during the process. The force exerted on the wall and the temperature at the centre of the charge was continuously monitored and the data obtained were transferred to a data acquisition system. During the charging and carbonization cycle, the temperature of the wall was kept constant at $1010^{\circ} \mathrm{C}$. The coking time was nearly $3 \mathrm{~h}$, the temperature in the centre of the charge reaching to $950{ }^{\circ} \mathrm{C}$ by the end of the coking cycle. After the hot coke was pushed from the oven, it was quenched with a water spray.

To assess the effect of the different plastic wastes, the coking tests were performed in similar charging (moisture, size distribution, bulk density) and coking conditions. The preparation of the charge was as close as possible for all the blends, i.e. a particle size of approximately $70 \mathrm{wt} . \%$ below $2 \mathrm{~mm}$ and $18 \mathrm{wt} . \%$ over $3 \mathrm{~mm}$ and; a moisture content between 6 and $8 \mathrm{wt} . \%$; and a bulk density of $785 \pm 30 \mathrm{~kg} / \mathrm{m}^{3}$ dry basis. The coking blend without any plastic waste addition was used as a reference and carbonized at three different bulk densities (778, 813 and $835 \mathrm{~kg} /$ $\mathrm{m}^{3} \mathrm{db}$ ). The bulk density was adjusted by adding water to the coal blend. The amount of mixed plastic waste added to the coking blend was $2 \mathrm{wt} \%$ in the form of irregular laminated pieces of $<10 \mathrm{~mm}$ in size.

\subsection{Coke quality}

The quality of the resultant cokes with a view to their use in a blast furnace was assessed in terms of their reactivity towards $\mathrm{CO}_{2}$ (CRI) and the mechanical strength of the partially-gasified coke (CSR index) as measured by the NSC method, following the ASTM D5341 standard procedure. The CRI is defined as the percentage of weight loss in a coke sample $(200 \mathrm{~g}, 19-22.4 \mathrm{~mm}$ in size) subjected to the action of $\mathrm{CO}_{2}$ at $1100^{\circ} \mathrm{C}$ for $2 \mathrm{~h}$. The CSR index is defined as the percentage of partially-gasified coke with a particle size of $>9.5 \mathrm{~mm}$ after mechanical treatment in a drum (600 revolutions at $20 \mathrm{rpm}$ ).

The cold mechanical strength was evaluated by rotating $10 \mathrm{~kg}$ of coke of $>50 \mathrm{~mm}$ initial size in a JIS drum for 150 revolutions. The $\mathrm{DI}_{15}^{150}$ index is defined as the amount of coke with a size of $<15 \mathrm{~mm}$, after mechanical treatment (JIS K2151 standard procedure).

The true density of the cokes was measured by means of helium picnometry in a AccuPyc1330T Micromeritics apparatus. The apparent densities were determined by two methods: (1) by water displacement using $300 \mathrm{~g}$ coke of the same particle size as that used to determine the coke reactivity towards $\mathrm{CO}_{2}(19-22.4 \mathrm{~mm})$ and (2) with mercury at $0.1 \mathrm{MPa}$. The open porosity of the cokes was calculated from the true helium and apparent densities. The pore volume and pore-size distribution in the range of $5.5 \mathrm{~nm}$ to $240 \mu \mathrm{m}$ were evaluated on a mercury Autopore IV 9500 Micromeritics porosimeter operating from a subatmospheric pressure of $0.005 \mathrm{MPa}$ to a maximum operational pressure of $227 \mathrm{MPa}$. The pore volume distribution was established as follows: $>100 \mu \mathrm{m}$ (from the difference between the pore volume calculated from helium and apparent water densities and the volume of pores of $<100 \mu \mathrm{m}$ determined by mercury porosimetry), $100-50 \mu \mathrm{m}$, 50-15 $\mu \mathrm{m}$ (large macropores or devolatilization pores); $15-1 \mu \mathrm{m}$ and $1 \mu \mathrm{m}$ to $50 \mathrm{~nm}$ (macropores); and $50-5.5 \mathrm{~nm}$ (mesopores). The micropore volume was estimated by subtracting the mercury macro- and mesopore volumes from the total pore volume. For the measurements, each coke sample (1-3 mm in size) was degasified at $200{ }^{\circ} \mathrm{C}$ overnight [24]. 


\section{Results and discussion}

Polyethylene occurring in two main forms (HDPE and LDPE, respectively), polypropylene (PP), polystyrene (PS) and polyethylene terephthalate (PET) are the major plastics found in municipal wastes with polyvinyl chloride (PVC) and biomass such as paper labels made of cellulose and other types of organic matter also being present in small amounts. In order to establish the effect of the quantity of these components for cokemaking, six plastic wastes of different composition were added to an industrial coking blend. The wastes were selected in such a way as to ensure a total amount of polyolefins of nearly 90 and 55 wt.\% for W1 and W4, respectively, while PS and PET range from 0 to nearly 20 wt.\% (Table 1 ). Single HDPE was included as a reference. The only limitation imposed on these wastes for use in cokemaking was that the PVC should not be higher than 2 wt.\%, to avoid corrosion problems arising from the hydrogen chlorine and chloro organic compounds present as light gas during the early stages of carbonization. Wastes W1A, W1B and W1C have similar compositions and they are the richest in polyolefins. They contain nearly $70 \mathrm{wt} . \%$ of HDPE and 20 wt.\% of PP together with small amounts of LDPE and PET ( 5 wt.\% each). The difference between W1A and W1C is that the latter is an unwashed waste. The remaining mixed plastics contain the six most common thermoplastics from household wastes, polyethylene -HDPE and LDPE-, PP, PS, PET and PVC in different proportions.

\subsection{Influence of plastic waste composition on Gieseler fluidity}

Gieseler fluidity has long been an important parameter for evaluating coking coals and their blending potential in complex blends of different coals (rank, coking capacity and geographical origin) in proportions such that the Gieseler maximum fluidity value is within an optimum range of $100-1000 \mathrm{ddpm}$ to ensure that the coke is of the required quality, as established for conventional coking charging [25]. When an additive is incorporated into the coal blend, it is important to know whether it is an enhancing, neutral or inhibiting agent for fluidity development. For this reason, all the plastic wastes were added to coal blend D in amounts of $2 \mathrm{wt} . \%$ and the mixtures were then subjected to Gieseler plastometry. Table 2 shows the maximum fluidity values (Fmax) and the characteristic temperatures for the main phenomena that occur during the transformation of coal to semicoke. All of the mixed plastic wastes experienced a decrease in maximum fluidity, but to different degrees, as reflected by the percentage loss (Table 2 ). The smallest reduction was experienced by the blends containing HDPE and approximately $90 \%$ polyolefins ( $<20 \%$ reduction), while the largest reduction (59\%) corresponded to the W4 waste. The latter contained the lowest amount of polyolefins (55 wt.\%) and, consequently, the highest amount of PS and PET. These data suggest that the relative proportion of polyolefins (PE and PP) to the other plastics, PS and PET is crucial for the development of fluidity in coal.

Table 2

Thermoplastic parameters of coal blend D and its mixtures with plastic wastes at the addition rate of 2 wt.\%.

\begin{tabular}{lllllll}
\hline Blend & $\begin{array}{l}\mathrm{Ts} \\
\left({ }^{\circ} \mathrm{C}\right)\end{array}$ & $\begin{array}{l}\mathrm{Tf} \\
\left({ }^{\circ} \mathrm{C}\right)\end{array}$ & $\begin{array}{l}\mathrm{Tr} \\
\left({ }^{\circ} \mathrm{C}\right)\end{array}$ & $\begin{array}{l}\mathrm{Tr}-\mathrm{Ts} \\
\left({ }^{\circ} \mathrm{C}\right)\end{array}$ & $\begin{array}{l}\text { Fmax } \\
(\mathrm{ddpm})\end{array}$ & $\begin{array}{l}\text { Fluidity loss } \\
(\%)\end{array}$ \\
\hline D & 406 & 449 & 491 & 85 & 214 & 0.0 \\
D2HDPE & 405 & 448 & 492 & 87 & 185 & 13.6 \\
D2W1A & 403 & 452 & 491 & 88 & 206 & 3.7 \\
D2W1B & 407 & 448 & 490 & 83 & 177 & 17.3 \\
D2W2 & 407 & 455 & 488 & 81 & 140 & 34.6 \\
D2W3 & 408 & 450 & 489 & 81 & 114 & 46.7 \\
D2W4 & 409 & 452 & 489 & 80 & 88 & 59.1 \\
\hline
\end{tabular}

The above results are in excellent agreement with those reported for the addition of single plastics such as HDPE, LDPE, PP, PS and PET to different coals [16-23]. In all cases, individual plastics cause a reduction in the Gieseler maximum fluidity (or an increase in the complex viscosity) of coking coals, the extent of the reduction depending on the nature and amount of the single plastic added and the coal used [16-23]. On the basis of these results, the following sequence for reduction in Fmax in ascending order has been established:

HDPE $\leqslant$ LDPE $<$ PP $\ll$ PS $<$ PET

The different degrees of reduction in fluidity induced by individual plastics have been attributed to the combined effect of the thermal stability of the polymers and the H-transfer from the coal to the plastic during co-pyrolysis. Thus, for ethylene-bridged polymers like HDPE and LDPE, decomposition appears to be rate-limited by the homolytic cleavage of the $\mathrm{C}-\mathrm{C}$ bonds which occurs close to the fluid range of coking coals. This type of polymer also has a limited ability to participate in $\mathrm{H}$-transfer reactions during the co-pyrolysis with coal. However, when ethylene units have a pendant group such as methyl in PP or phenyl in PS, decomposition takes place at a lower temperature than polyethylene and at a higher temperature than those polymers with ethylene bridges adjacent to an aromatic ring and an ester functionality like PET. The less thermally stable polymers have a greater tendency to accept hydrogen for the stabilization of the free radicals generated during co-pyrolysis. They therefore reduce fluidity into greater extent [19].

Taking into account the above considerations, two different groups of single plastics can be established. Plastics in the first group include the three polyolefins, HDPE, LDPE and PP, which moderately reduce the fluidity of the coal or coal blends; while those in the second group, PS and PET which have benzene rings incorporated into their polymer backbone with or without the presence of heteroatoms, are strong modifiers of the thermoplastic properties of the coal. The relative proportion of these two plastic groups in the waste is the controlling factor in the reduction of fluidity.

Fig. 1 shows the Gieseler maximum fluidity of blends as a function of the amount of the polyolefins (plastics of type 1) in the waste. Although some deviations from linearity are observed, especially in the wastes containing >90 wt.\% polyolefins, it is clear that the lower the amount of the polyolefins in the waste, the greater the loss fluidity experienced by the coal + plastic blends. The temperatures at which coal reaches the Fmax value (Tf), starts to soften (Ts) and, finally, resolidifies into semicoke $(\mathrm{Tr})$ are not affected by the 2 wt.\% addition of plastic wastes. The characteristic temperatures are, in general, the same or show differences of $<3^{\circ} \mathrm{C}$.

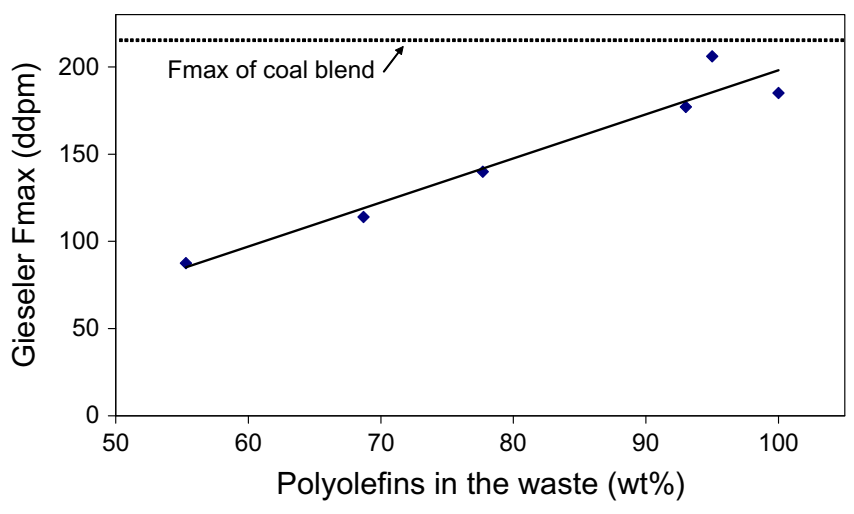

Fig. 1. Variation of the Gieseler maximum fluidity (Fmax) of coal blend D as a function of the amount of polyolefins in the waste. 


\subsection{Influence of plastic waste composition on the development of coking pressure}

Co-carbonizations of coal blend D and its mixtures with the multicomponent plastic wastes studied were carried out in a semipilot movable wall oven in order to measure the coking pressure generated during the process and to obtain enough coke to enable its quality to be evaluated. The plastic wastes added to the coal blend were washed and cut into small laminated pieces of less than $10 \mathrm{~mm}$ in size. It should be noted that generally the separated recycled plastics are granulated or pelletized, melted or partiallymelted and then extruded to form the end product. However, the mixed plastics selected in this work for feedstock recycling in coke ovens require a minimum of pre-processing in order to avoid secondary effects of the pelletization of the plastics and to reduce the cost of the feedstock.

The bulk density of the charge is an important factor that affects the coking pressure, throughput and coke quality [26-28]. In order to avoid secondary effects from variations in the bulk density on the development of coking pressure, the particle size distribution and the moisture content of the coal were careful controlled to allow only minor variations in bulk density. To evaluate the effect of plastic waste addition on coking pressure, the reference coal blend without plastic wastes was carbonized at three different bulk densities by adding water. The moisture contents of the reference blend were 4.6, 5.7 and $8.1 \mathrm{wt} . \%$, giving bulk densities of 835 , 813 and $778 \mathrm{~kg} / \mathrm{m}^{3}$ dry basis $(\mathrm{db})$ and coking pressures of 12,8 and $5 \mathrm{kPa}$, respectively. The coking pressure progressively increases from 5 to $12 \mathrm{kPa}$ due to the increasing bulk density (decreasing moisture content), which makes it more difficult for the gas to escape. It should be noted that the increase in coking pressure with bulk density does not follow a linear pattern, it is exponential. From the results two important points stand out: (i) the force exerted by the coal charge at the highest bulk density tested does not exceed the safe limit established for this oven $(20 \mathrm{kPa})$ and (ii) although a high bulk density of $835 \mathrm{~kg} / \mathrm{m}^{3} \mathrm{db}$ is not usual for conventional coke ovens, it was nevertheless tested in order to show the effects that bulk density can have on the coking pressure developed by the reference coal blend. Consequently, co-carbonizations with plastic wastes were only performed with bulk densities of between 778 and $813 \mathrm{~kg} / \mathrm{m}^{3} \mathrm{db}$ and blend moisture contents of between 6 and 8 wt.\%.

All the mixed plastic wastes have a marked effect on the coking pressure generated during carbonization. When $2 \mathrm{wt} . \%$ of plastic is added, the coking pressure seems to be dependent on the relative proportions of the two polymer groups present in the waste (polyolefins and aromatic polymers), defined on the basis of the reduction in Gieseler fluidity (Fig. 2). The single HDPE produces an excessive coking pressure of close to $50 \mathrm{kPa}$ at a bulk density of $780 \mathrm{~kg} / \mathrm{m}^{3} \mathrm{db}$, about four times greater than the reference coal blend carbonized at the highest bulk density of $835 \mathrm{~kg} / \mathrm{m}^{3} \mathrm{db}$. The high pressure caused by HDPE is consistent with the studies of Nomura and Kato [10] who use polyethylene in the form of powder or beads. The first point to note from Fig. 2 is that the coking pressure progressively decreases as the amount of polyolefins in the waste decreases. Thus, when waste W4 with $55 \mathrm{wt} . \%$ of polyolefins and about $35 \mathrm{wt} . \%$ of PS + PET is added to the blend, the coking pressure is considerably reduced and it reaches a safe pressure value equivalent to that of the coal blend carbonized at a high bulk density (13 kPa vs. $12 \mathrm{kPa}$ for the coal blend) to which no plastic waste was added. Consequently, it can be deduced that aromatic polymers such as PET and PS have a beneficial effect on the force generated on the coke oven wall and that they help to balance the unsafe coking pressure generated by the polyolefins. Although only a limited number of plastic wastes was tested, from the relation between the amount of polyolefins and the coking pressure

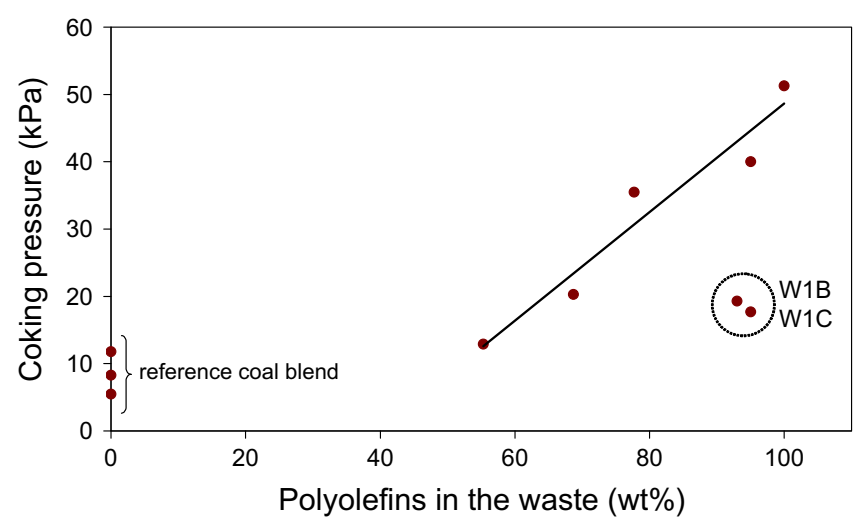

Fig. 2. Variation of the pressure generated during the coking process with the amount of total polyolefins in the waste.

represented in Fig. 2, it is inferred that an upper limit of around $65 \mathrm{wt} . \%$ should be set for the amount of polyolefins in a waste in order to avoid higher pressures than $20 \mathrm{kPa}$. However, further research is needed to determine whether the amount of polyolefins permissible can be taken as a generally applicable upper limit or whether the coal characteristics and coking conditions also need to be considered.

Two blends containing plastic wastes with similar amounts of HDPE and PP (around 70 and 20 wt.\%, respectively) lie outside the general trend and yield lower coking pressure values than expected. One of them corresponds to the unwashed plastic waste W1C which contains biomass (garbage, vegetal materials, etc.) and the other corresponds to the waste W1B which contains 2 wt.\% cellulose. These results suggest that the presence of such materials as minor components in the wastes have a beneficial effect on the coking pressure developed during the process.

During the transformation of coal to coke, gaseous and vapour products are released in different quantities and at different stages. From several studies on the mechanisms that govern the generation of pressure during carbonization, two inter-related phenomena have been proposed as the factors that might be responsible for the build-up of dangerous pressure in the coke ovens: the quantity and composition of the thermal degradation products from the coal and the way in which the gaseous and vapour products evolve which affect permeability of the charge. When low permeability occurs, there is a resistance to the gaseous and vapour products to escape and, in turn, increase the coking pressure [29-31]. When multicomponent plastic wastes are added, the polymers behave differently during thermal treatment. Thermogravimetric analyses (TG) of the different single plastics have shown that the generation of non-condensable and condensable products from PS and PET occurs at a lower temperature and prior to the development of coal fluidity, while the thermal degradation of polyolefins occurs when coal is in the stage of fluidity development. Thus, the temperature gap between coal and polymer decomposition is wider for PET and PS than for polyolefins [17,19-21]. It should be mentioned that PET and PS exhibit an earlier stage of gas evolution, which decreases the fluidity reached during co-carbonization with coal and inhibits the formation of anisotropic carbon in the coke structure [19]. In this case no negative effect on coking pressure is to be expected. However, polyolefins and specially polyethylenes generate the degradation products in the stages which are considered suitable for the development and maintenance of fluidity in the coking system. In such cases, the possibility that the composition of the pyrolysis products from the polyolefins and their chemical reactivity cause modifications in the coking pressure should be considered. The pyrolysis of the two groups of plastics in various experimental 
conditions and oven designs has been described by several authors $[18,32-38]$. When single plastics are pyrolyzed they give rise to hydrocarbons and other gases (condensable and non-condensable) with variable amounts of char. The pyrolysis products from polyolefins are dominated by an oil/wax fraction which is made up of long-chain alkanes, alkenes and alkadienes. The focus of our attention will be the oil/wax fraction. The three polyolefins produce very similar yields of oil/waxes, with particularly high yields at the temperatures of 500 and $600{ }^{\circ} \mathrm{C}$ (>80 wt.\% of the pyrolysis products). The wax and the oil are made up of a complex mixture of hydrocarbons which differ in their molecular weight distribution. For instance, in the pyrolysis of LDPE the molecular weight distribution of the oils ranged from 60 to 1500 Da while that of the waxes ranged from 60 to $4000 \mathrm{Da}$. These compositional differences gave rise to a high viscous fraction (wax) and relatively low viscosity oil [3238].

Moreover, it has previously been shown that in the semicokes obtained from the co-carbonization of coal and polyolefins at $500{ }^{\circ} \mathrm{C}$, two different carbon phases arise. One carbon phase corresponds to the anisotropic matrix formed from the polymerization of coal, while the other carbon phase results from certain degradation products from polyolefins. These include waxy hydrocarbons which are trapped inside the semicoke structure and, then, released as alkanes at higher temperatures $[19,20]$. It is postulated that a certain amount of degradation products from polyolefins are stabilized by hydrogen radicals from the coal and they leave the co-carbonizing system as alkanes, alkenes and alkadienes (primary oil/waxes). However, another fraction of long-chain free radicals from polyolefins persists on the semicoke inner surfaces. Wax-like compounds therefore have difficulty in escaping along the coal charge in the oven at low temperatures $\left(<500^{\circ} \mathrm{C}\right)$. As a result, the gas pressure in the co-carbonizing system increases, becoming extremely high when polyolefins are the main constituents of the waste. As the temperature gradually increases $\left(>500{ }^{\circ} \mathrm{C}\right)$ a secondary cracking of polyolefin fragments incorporated into the semicoke matrix takes place during the post-plastic coal stage, as a result of which the amount of aliphatic hydrocarbons in the tar and the amount of light hydrocarbons in the gas fraction increases. In summary, the high viscosity of waxes from polyolefins is consistent with a low permeability of the coking charge and, in turn, an increase in the coking pressure.

\subsection{Influence of plastic waste composition on coke quality}

The addition of $2 \mathrm{wt} . \%$ plastic waste improves the mechanical strength of the cokes in terms of the DI150/15 index by 1-4 points (Fig. 3). However, no clear relation was found between this coke property and the composition of the wastes (Fig. 4). It is important to point out that the strength indices of the cokes obtained in the semipilot oven are lower than those from industrial cokes, because of wall effects and different carbonization conditions [39]. Nevertheless, a comparison of the strength indices of the cokes is useful to establish the effects of the plastic wastes on this coke property. As regards CRI and CSR, an improvement in the mechanical strength of the partially-gasified coke (CSR index) by about 5 points was caused by the addition of HDPE, whereas HDPE had no influence on reactivity towards $\mathrm{CO}_{2}$ (CRI) (Fig. 5). The other wastes increase their CRI from $28 \%$ to $32 \%$ as the amount of the aromatic polymers of type 2 (PS and PET) increases in the waste. This is clearly reflected in the relation between the amount of polyolefins in the waste and the CRI (Fig. 6). In general, as the amount of the polyolefins in the waste decreases and the amount of PS and PET increases, the cokes produced become more reactive. It can be concluded, therefore, that the ratio of the polyolefins to PS + PET is crucial, not only for the development of coking pressure, but also

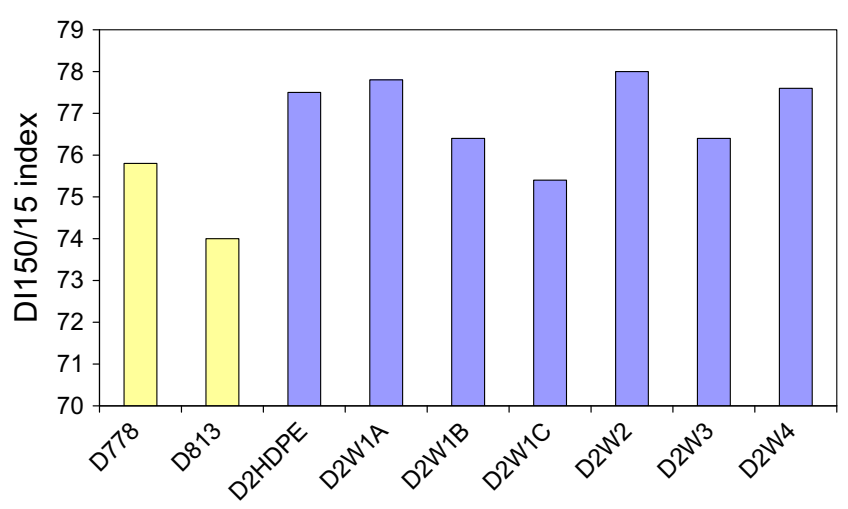

Fig. 3. Variation of the mechanical strength DI150/15 index of the cokes produced from coal blend D with and without plastic waste addition. D778 and D813 denote cokes produced from the base coal blend D at two bulk densities, 778 and $813 \mathrm{~kg} /$ $\mathrm{m}^{3} \mathrm{db}$.

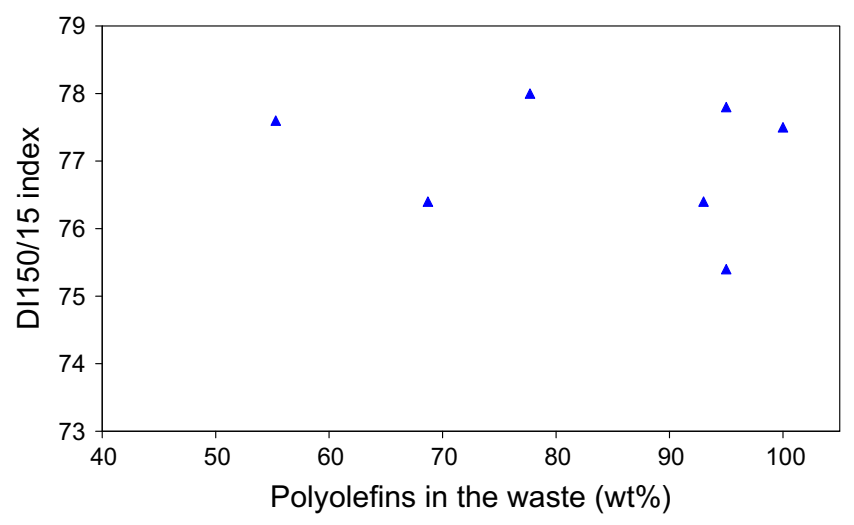

Fig. 4. Variation of the amount of polyolefins in the plastic waste added at 2 wt.\% to the coal blend and the mechanical strength DI150/15 index of the cokes produced at a semipilot scale.

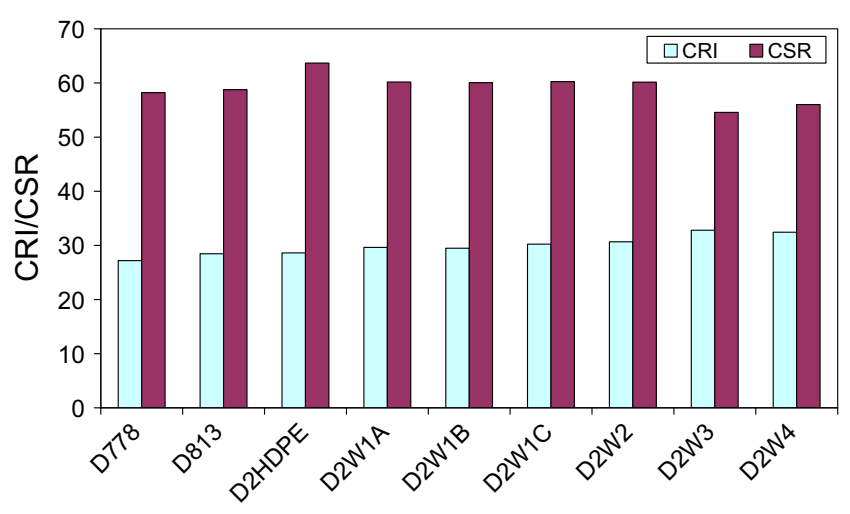

Fig. 5. Variation of CRI and CSR indices of the cokes produced from coal blend D with and without plastic waste addition. D778 and D813 denote cokes produced from the base coal blend $\mathrm{D}$ at two bulk densities, 778 and $813 \mathrm{~kg} / \mathrm{m}^{3} \mathrm{db}$.

for the reactivity towards $\mathrm{CO}_{2}$ and mechanical properties of the coke, specially of the partially-gasified coke.

Variations in the viscosity of the coal charge and the amount of volatile products released during the plastic and post-plastic stages affect the final porous structure of the resultant cokes. In the case of charges made up of coal plus plastics, the amount of volatiles released during the fluid stage and the incorporation of waxy 


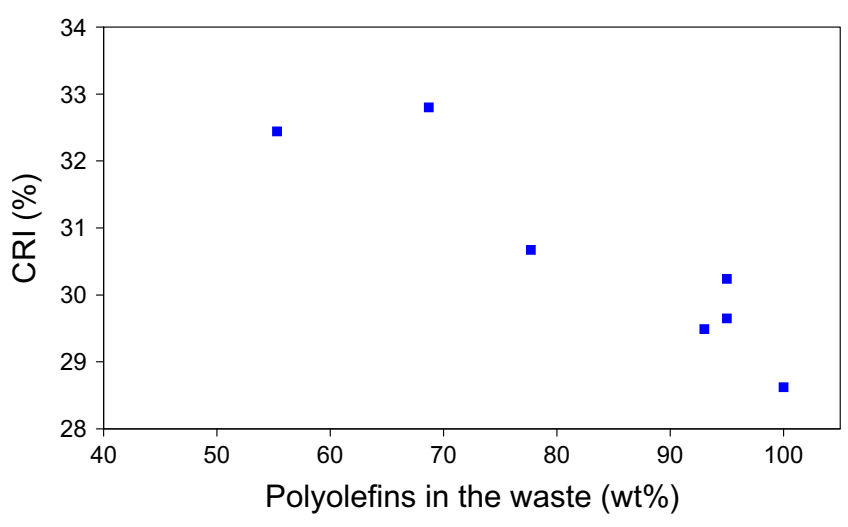

Fig. 6. Relation between the amount of polyolefins in the plastic waste added at $2 \mathrm{wt}$.\% to the coal blend and the reactivity towards $\mathrm{CO}_{2}$ of the cokes produced at a semipilot scale.

Table 3

Density and porosity values of the cokes from coal blend D with and without plastic waste addition.

\begin{tabular}{llllll}
\hline Coke & $d_{\mathrm{He}}{ }^{\mathrm{b}}\left(\mathrm{g} / \mathrm{cm}^{3}\right)$ & $d_{\mathrm{ap}}{ }^{\mathrm{c}}\left(\mathrm{g} / \mathrm{cm}^{3}\right)$ & $\varepsilon^{\mathrm{d}}(\%)$ & $d_{\mathrm{Hg}}{ }^{\mathrm{e}}\left(\mathrm{g} / \mathrm{cm}^{3}\right)$ & ${\varepsilon^{\prime}}^{\mathrm{f}}(\%)$ \\
\hline $\mathrm{D}^{\mathrm{a}}$ & 1.850 & 0.894 & 51.7 & 1.565 & 15.4 \\
D2HDPE & 1.847 & 0.895 & 51.5 & 1.495 & 19.1 \\
D2W1A & 1.846 & 0.881 & 52.3 & 1.485 & 19.5 \\
D2W1B & 1.837 & 0.874 & 52.4 & 1.489 & 18.9 \\
D2W1C & 1.852 & 0.856 & 53.8 & 1.444 & 22.0 \\
D2W2 & 1.838 & 0.898 & 51.1 & 1.472 & 19.9 \\
D2W3 & 1.842 & 0.865 & 53.0 & 1.491 & 19.1 \\
D2W4 & 1.832 & 0.883 & 51.8 & 1.447 & 21.0 \\
\hline
\end{tabular}

a Coke produced from the coal blend $\mathrm{D}$ at a bulk density of $778 \mathrm{~kg} / \mathrm{m}^{3}$.

b True helium density of the coke.

c Apparent density of the coke determined by water displacement.

d Coke porosity calculated from helium and apparent (water) densities.

e Apparent density determined in mercury at $0.1 \mathrm{MPa}$.

${ }^{\mathrm{f}}$ Coke porosity calculated from helium and apparent (mercury at $0.1 \mathrm{MPa}$ ) densities.

hydrocarbons within the co-carbonization system with their subsequent release in the post-plastic stage as described above, are the phenomena responsible for modifying the formation of pores in the final coke. Although the helium density varies little from coke to coke, ranging from 1.832 to $1.852 \mathrm{~g} / \mathrm{cm}^{3}$ (Table 3 ), cokes produced by the addition of plastic waste are, in general, less dense than those produced from the reference coal blend D. In addition, the apparent density as determined by water displacement which represents the total volume of the coke, including fine and large pores and fine fissures remains unchanged or is even lower. Consequently, changes in the total open porosity of the cokes depend on

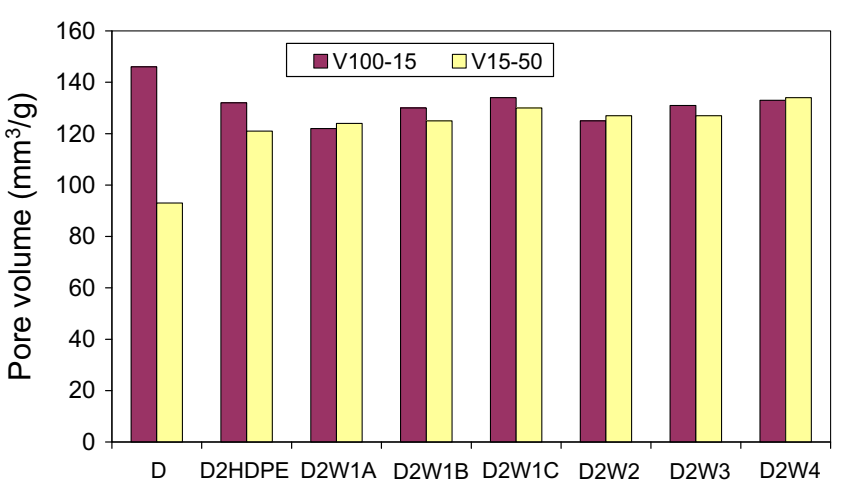

Fig. 7. Pore volume distributions for cokes from the coal blend $\mathrm{D}$ with and without plastic waste addition. ( $V_{100-15}$ and $V_{15-50}$ are the pore volumes in the size range between 100 and $15 \mu \mathrm{m}$ and between $15 \mu \mathrm{m}$ and $50 \mathrm{~nm}$, respectively).

both true and apparent densities. The total open porosities ranged from $51 \%$ to $54 \%$ (Table 3 ) and correspond to pore volumes between 570 and $628 \mathrm{~mm}^{3} / \mathrm{g}$ (Table 4). Over $50 \%$ of the volume is occupied by large pores with a diameter greater than $100 \mu \mathrm{m}$, whereas the remainder is made up of pores with a diameter between 100 and $15 \mu \mathrm{m}$, between $15 \mu \mathrm{m}$ and $50 \mathrm{~nm}$ and less than $50 \mathrm{~nm}$ in proportions of $20-25 \%, 16-23 \%$ and $<5 \%$, respectively. This pore-size distribution clearly reflects the macroporous structure of the metallurgical cokes. The mesopore and micropore volumes are less than $13 \mathrm{~mm}^{3} / \mathrm{g}$ and $6 \mathrm{~mm}^{3} / \mathrm{g}$, respectively, with the exception of the coke produced from the blend containing waste W1C. This coke has a high micropore volume of $19 \mathrm{~mm}^{3} / \mathrm{g}$. The high microporosity of the coke may be due to the difference between the composition of this plastic waste and wastes W1A and W1B. Waste W1C has the same proportion of each type of plastic as $\mathrm{W} 1 \mathrm{~A}$, with the difference that $\mathrm{W} 1 \mathrm{C}$ has not been washed. Thus, the minor components of this waste seem to play an important role in the development of pores of a smaller size.

It is clear from the percentage of porosities calculated from true helium and apparent mercury at $0.1 \mathrm{MPa}$, that the cokes produced from blends with plastic wastes have a higher porosity in this size range (Table 3). From the pore-size distribution, it is also clear that no general statements about the effects of plastic waste addition can be made for cavities larger than $100 \mu \mathrm{m}$ and pores smaller than $50 \mathrm{~nm}$. However, the most significant porosity changes that affect the large macroporosity, i.e. between 100 and $15 \mu \mathrm{m}$, and the macroporosity, $15 \mu \mathrm{m}$ and $50 \mathrm{~nm}$ may be due to the addition of waste (Fig. 7). The volume of larger pores in cokes with plastics addition is in all cases lower than for the coke obtained from coal blend D. Accordingly a decrease in macropores (15 $\mu \mathrm{m}$ and $50 \mathrm{~nm})$ is observed in these cokes.

Table 4

Pore size distribution of cokes produced from coal blend D and its mixtures with plastic wastes.

\begin{tabular}{|c|c|c|c|c|c|c|c|c|}
\hline & $\mathrm{Vt}^{\mathrm{a}}\left(\mathrm{mm}^{3} / \mathrm{g}\right)$ & $V_{>100}{ }^{\mathrm{b}}\left(\mathrm{mm}^{3} / \mathrm{g}\right)$ & $V_{100-50}{ }^{\mathrm{c}}\left(\mathrm{mm}^{3} / \mathrm{g}\right)$ & $V_{50-15^{\mathrm{c}}}\left(\mathrm{mm}^{3} / \mathrm{g}\right)$ & $V_{15-1}^{\mathrm{c}}\left(\mathrm{mm}^{3} / \mathrm{g}\right)$ & $V_{1-50}^{\mathrm{c}}\left(\mathrm{mm}^{3} / \mathrm{g}\right)$ & $V_{50-5.5^{\mathrm{c}}}\left(\mathrm{mm}^{3} / \mathrm{g}\right)$ & $V_{<5.5^{\mathrm{d}}}\left(\mathrm{mm}^{3} / \mathrm{g}\right)$ \\
\hline $\mathrm{D}$ & 578 & 325 & 66 & 80 & 54 & 39 & 10 & 4 \\
\hline D2HDPE & 576 & 309 & 56 & 76 & 71 & 50 & 9 & 5 \\
\hline D2W1A & 593 & 331 & 46 & 76 & 72 & 52 & 11 & 5 \\
\hline D2W1B & 600 & 334 & 55 & 75 & 72 & 53 & 10 & 1 \\
\hline D2W1C & 628 & 334 & 60 & 74 & 73 & 57 & 11 & 19 \\
\hline D2W2 & 570 & 302 & 49 & 76 & 73 & 54 & 11 & 5 \\
\hline D2W3 & 613 & 343 & 55 & 76 & 73 & 54 & 11 & 1 \\
\hline D2W4 & 587 & 301 & 56 & 77 & 79 & 55 & 13 & 6 \\
\hline
\end{tabular}

a Total pore volume $(\mathrm{Vt})$ calculated from the true helium and apparent water densities.

b Estimated from the difference between the total volume (Vt) and the sum of the volumes of pores with $<100 \mu \mathrm{m}$ in diameter determined by mercury porosimetry.

c Pore volume in the size ranges: $100-50 \mu \mathrm{m} ; 50-15 \mu \mathrm{m} ; 15-1 \mu \mathrm{m} ; 1 \mu \mathrm{m}$ to $50 \mathrm{~nm}$; 50-5.5 nm (mesopores) determined by mercury porosimetry.

d Volume of pores $<5.5 \mathrm{~nm}$ (micropores) estimated by subtraction of all macro- and mesopore volume from the total pore volume (Vt). 
It is well known that the porous structure (volume fraction, morphology and size distribution) is of great importance for the mechanical strength and reactivity towards $\mathrm{CO}_{2}$ [40-43]. However, the porosity data obtained for this series of cokes do not show a clear relationship between the changes in strength and those of reactivity, and porosity. The addition of plastic wastes to coal is expected to modify the order and size of the crystalline structure of the cokes. Any variations in strength and reactivity therefore must be due to changes in both the porosity and the optical texture of the cokes.

\section{Conclusions}

Metallurgical coke manufacture is a valuable alternative to the feedstock recycling of mixed plastic wastes. The key compositional parameters of these feedstocks are directly linked to the relative proportions of the polyolefins and the aromatic polymers -PS plus PET-. As the total amount of polyolefins increases, the pressure exerted on the wall also increases. To avoid the risk of wall damage and the deterioration of coke quality, the composition of the waste added to the coal blend needs to be carefully controlled. A mechanism for the generation of high coking pressures caused by the addition of polyolefins is proposed taking into account the inter-related phenomena that occur during the co-carbonization of coal and plastics: (i) the carbonization stage when coal is transformed into semicoke-coke and thermal decomposition of the plastics takes place; (ii) the yield and composition of degradation products from the plastics; and (iii) the heavy hydrocarbon fragments formed during the pyrolysis of polyolefins incorporated inside the coal and semicoke inner surface, which are released at much higher temperatures, after the fluid coal has resolidified, and condense as oil and wax in the tar. All the above phenomena are controlled by the chemical composition of the waste, which determines whether coal and plastics are compatible for carbonization so that pressure remains within a safe range. The best quality coke was obtained by the addition of single HDPE, and the coke reactivity seems to be affected by the addition of the other mixed plastic wastes. In addition, polyolefin-enriched wastes which contain a small amount of organic materials that are different to polymers have a negative effect on coke quality. In general, the cokes produced by the plastic addition are less dense and more macroporous and the pores become smaller. In summary, the ratio of polyolefins to polyaromatic polymers (PS and PET) present in the waste is critical for cokemaking, since this ratio determines not only the fluidity of the coal blend but also the wall pressure generated during the process and the quality of the coke produced in terms of reactivity towards $\mathrm{CO}_{2}$ and mechanical strength after reaction. An amount of polyolefins lower than $65 \mathrm{wt} . \%$ in the waste was established to avoid negative effects on the coking pressure generation.

\section{Acknowledgements}

The financial support provided by the Spanish Ministry of Education and Science through research Project CTM2004-03254 is gratefully acknowledged. We also thank Abornasa and ArcelorMittal for participating in the project and for providing the post-consumer plastic wastes used for this research and the industrial coal blend. S.M. acknowledges the predoctoral grant from PCTIAsturias.

\section{References}

[1] Janz J, Weiss W. Injection of waste plastics into blast furnace of Stahlwerke Bremen. In: 3rd International cokemaking congress, CRM-VDEh, Gent, Belgium; 1996, p. 114-9.
[2] Asanuma M, Ariyama T, Sato M, Murai R, Nonaka T, Okohi I, et al. Development of waste plastics injection process in blast furnace. ISIJ Int 2000;40(3):244-51.

[3] Wakimoto K. A feedstock recycling system of waste plastics in a blast furnace at NKK. In: 60th Ironmaking conference proceedings, ISS; 2001. p. 473-83.

[4] Buchwalder J, Scheidig K, Schingnitz M, Scmöle P. Results and trends on the injection of plastics and ASR into the blast furnace. ISIJ Int 2006;46(12):1767-70.

[5] Hanrot F, Sert D, Delinchant J, Pietruck R, Bürgler T, Babich A et al. $\mathrm{CO}_{2}$ mitigation for steelmaking using charcoal and plastics wastes as reducing agents and secondary raw materials. In: López FA, Puertas F, Alguacil FJ, Guerrero A, editors. Proceedings of the 1st Spanish national conference on advances in materials recycling and eco - energy Madrid, Spain; 2009, paper S05-4. <http://hdl.handle.net/10261/18433>.

[6] Asanuma M, Kajioka M, Kuwabara M, Fukumoto Y, Terada K. Establishment of advanced recycling technology for waste plastics in blast furnace. JFE Tech Rep 2009;3:34-40.

[7] Goto H, Ibaraki T, Kondh H, Koseki T, Matsuguma H. Plastics recycling by a coke-oven from wastes plastics to chemical raw materials. Nippon Steel Tech Rep 2002;86:10-3.

[8] Kato K, Nomura S, Uematsu H. Development of waste plastics recycling process using coke ovens. ISIJ Int 2002;42:S10.

[9] Nomura S, Kato K. Basic study on separate charge of coal and waste plastics in coke oven chamber. Fuel 2005;84:429-35.

[10] Nomura S, Kato K. The effect of plastic size on coke quality and coking pressure in the co-carbonization of coal/plastic in coke oven. Fuel 2006;85:47-56.

[11] Kato K, Nomura S, Fukuda K, Uematsu H. Chlorine behaviour of coal and waste plastics during carbonization. In: Iron and steel technology, AISTech; 2008. p. 21-30.

[12] Krisham SH, Sharm R, Dash PS, Haldar SK, Biswas B. Use of waste plastics in cokemaking at Tata steel. Ironmak Steelmak 2006;33(4):200-92.

[13] Diez MA, Alvarez R, Canga CS, Barriocanal C, Gayo F, Domínguez A. Cocarbonization of coal with LDPE and HDPE plastic waste at three different scales. In: International conference on carbon, vol. II; 2000. p. 717-8.

[14] Diez MA, Alvarez R, Barriocanal C, Melendi S. Possibilities of the coking process for the recycling of plastic wastes. In: Eurocoke summit 2007, Intertech-Pira, Nice, France; 2007

[15] Diez MA, Alvarez R, Melendi S, Barriocanal C. Feedstock recycling of plastic wastes/oil mixtures in cokemaking. Fuel 2009;88:1937-44.

[16] Melendi S, Diez MA, Alvarez R, Barriocanal C. Plastic wastes, lube oils and carbochemical products as secondary feedstocks for blast-furnace coke production. Fuel Process Technol, doi:10.1016/i.fuproc.2010.10.014

[17] Diez MA, Alvarez R, Barriocanal C, Canga CS. Modification of coal thermoplastic properties by plastic waste. In: International conference on carbon, vol. II; 2000. p. 719-20.

[18] Dominguez A, Blanco CG, Barriocanal C, Alvarez R, Diez MA. Gas chromatographic study of the volatile products from co-pyrolysis of coal and polyethylene wastes. J Chromatogr A 2001;918:135-44.

[19] Diez MA, Barriocanal C, Alvarez R. Plastics wastes a modifiers of the thermoplasticity of coal. Energy Fuels 2005;19:2304-16.

[20] Vivero L, Barriocanal C, Alvarez R, Diez MA. Effects of plastic wastes on coal pyrolysis behavior and the structure of semicokes. J Anal Appl Pyrol 2005;74:327-36

[21] Nomura S, Kato K, Nakagawa T, Komaki I. The effect of plastic addition on coal caking properties during carbonization. Fuel 2003;82:1775-82.

[22] Sakurovs R. Interactions between coking coals and plastics during copyrolysis. Fuel 2003;82:1911-6.

[23] Castro Díaz M, Edecki L, Steel KM, Patrick JW, Snape CE. Determination of the effects caused by different polymers on coal fluidity during carbonization using high-temperature $1 \mathrm{H}$ NMR and rheometry. Energy Fuels 2008;22:471-9.

[24] Alvarez R, Pis JJ, Diez MA, Barriocanal C, Menéndez JA, Casal MD, et al Carbonization of wet and preheated coal. Effect on coke quality and its relation with textural properties. J Anal Appl Pyrol 1996;38:119-30.

[25] Okuyama Y, Miyazu T, Sugimura H, Kumagai M. Prediction of the coking property of coal by microscopic analysis. J. Fuel Soc Jpn 1970;49(522):736-43.

[26] Loison R, Foch P, Boyer A. Coke quality and production. London: Butterworth; 1989.

[27] Monson JR. Hypotheses on generation and effects of coking pressure. Cokemak Int 1992:3-4

[28] Tucker J, Everitt G. Coking pressure. Its causes, measurement and control. In: 2nd International cokemaking congress proceedings, London, vol. 2; 1992. p. 40-61.

[29] Marzec A, Czajkowska S, Álvarez R, Pis JJ, Diez MA. Studies on generation of excessive coking pressure. 2. Field ionization mass spectrometry of coals showing different contraction during carbonization. Energy Fuels 1997:11:982-6.

[30] Casal MD, Canga CS, Diez MA, Alvarez R, Barriocanal C. Low-temperature pyrolysis of coals with different coking pressure characteristics. J Anal Appl Pyrol 2005;74:96-103.

[31] Casal MD, Díaz-Faes E, Alvarez R, Diez MA, Barriocanal C. Fuel 2006;85:281-8.

[32] Buekens A. Introduction to feedstock recycling of plastics. In: Scheirs J, Kaminsky W, editors. Feedstock recycling and pyrolysis of waste plastics. John Wiley \& Sons Ltd.; 2006. p. 3-41 [chapter 1].

[33] Williams PT, Williams EA. Fluidised bed pyrolysis of low density polyethylene to produce petrochemical feedstock. J Anal Appl Pyrol 1999;51:107-26. 
[34] Williams EA, Williams PT. The pyrolysis of individual plastics and a plastic mixture in a fixed bed reactor. J Chem Technol Biotechnol 1997;70:9-20.

[35] Williams EA, Williams PT. Recycling plastic waste by pyrolysis. J Inst Energy 1998;71:81-3.

[36] Williams PT, Williams EA. Interaction of plastics in mixed-plastics pyrolysis Energy Fuels 1999;13:188-96.

[37] Kaminsky W. Chemical recycling of mixed plastics by pyrolysis. Adv Polym Technol 1995;14(4):337-44

[38] Kaminsky W, Schlesselmann B, Simon C. Olefins from polyolefins and mixed plastics by pyrolysis. J Anal Appl Pyrol 1995;32:19-27.

[39] Chatterjee A, Prasad HN. Possibilities of tar addition to coal as a method of improving coke strength. Fuel 1983;62:591-600.
[40] Patrick JW, Wilkinson HC. Factors influencing the strength of coke at high temperature. Mexborough: Coke Oven Managers' Association Year-book; 1977. p. 245-62.

[41] Patrick JW, Walker A. Porosity and strength of carbon materials. In: Patrick JW editor. Porosity in carbons: characterization and applications. London: Edward Arnold; 1995. p. 195-208. Chapter 7.

[42] Mühlen H-J, van Heek KH. Porosity and thermal reactivity. In: Patrick JW editor. Porosity in carbons: characterization and applications. London: Edward Arnold; 1995. p. 131-50 [chapter 5].

[43] Marsh H, Clarke DE. Mechanisms of formation of structure within metallurgical coke and its effect on coke properties. Erdöl Kohle $1986 ; 39(3): 113-22$. 